\title{
3 Wellcomensis MS.MSL.14 as a therapeutic handbook
}

\author{
Barbara Zipser
}

At first sight, MS.MSL.14 seems rather inconspicuous. ${ }^{1}$ It is a very small pocket-sized book which has obviously been handled and perused extensively. A number of pages at the end of the volume were added at a later time. The book was also exposed to water, which deleted text around the edges, but, in most cases, only over an area of just about one square centimetre. Many of the pages are torn, and sometimes held together by rough, thick thread, or simply missing. But it is precisely this fact that makes the book of particular interest. It is not a scholarly copy that was preserved in a pristine state in an ivory tower such as a major national library. Rather, it was a book that had been used in medical practice.

The book was all but forgotten in the centuries that followed, but over recent years been the subject of several studies. It was catalogued by Petros Bouras-Vallianatos $^{2}$ and its provenance has been described by Vivian Nutton and myself. ${ }^{3}$ Later on, I also analysed its thematic structure and edited some annotations in invisible ink. ${ }^{4}$ The manuscript was also a key witness for my first edition of John Archiatros' Iatrosophion. ${ }^{5}$ Yet, there is a middle section of the book that still needs further scholarly attention, which is the topic of this paper.

Here is a very rough summary of the contents of the main part of MS. MSL.14, omitting the sheets of paper that were added later at the end of the book (i.e. pp. 272-317): ${ }^{6}$

1. Ps.-Hippocrates, Letter to King Ptolemy On the Nature of Man, p. 1, 1. 1-p. 12, 1. 12.

\footnotetext{
1 Some of the material used for this paper was compiled during my postdoctoral fellowship at the Wellcome Trust Centre at UCL (072287).

2 Bouras-Vallianatos (2015: 283-6).

3 Nutton and Zipser (2010).

4 Zipser (2013)

5 Zipser (2009).

6 For further bibliography, see Nutton and Zipser (2010) and Bouras-Vallianatos (2015: 286).
} 
2. Ps.-Hippocrates, On the Human Body and Conception, p. 12, 1. 12-p. 14, 1. 19.

3. Brief text on bloodletting, p. 14, 1. 19-p. 16, 1. 19.

4. Brief text on conception, p. 17, 1. 1-p. 18, 1. 16.

5. Collection of remedies, p. 18, 1. 17-p. 34, 1. 17.

6. Ps.-Hippocrates, Sayings about Life and Death, p. 34, 1. 17-p. 44, 1. $4 .^{7}$

7. Ps.-Esdras, On Illuminating Days, p. 44, 1. 4-p, 46, 1. 5.

8. Compilation of recipes, p. 46, 1. 6-p. 76, 1. 14.

9. A therapeutic text, in part consistent with John Archiatros, Iatrosophion, p. 76, 1. $14-$ p. 81 .

10. Collection of remedies, pp. 84-107.

11. John Archiatros, Iatrosophion, pp. 122-3, 120-1, 126-7, 124-5, 128-271, 82-3.

The manuscript has a clearly defined structure, with items one to seven on the first 46 pages presenting introductory material, including a substantial proportion of Pseudo-Hippocratic content. This section was probably copied in its entirety from another source. ${ }^{8}$ It is followed by 225 pages of therapeutic content with a substantial part of the content consisting of recipes. Such a structure would make sense, as it creates a book that contains all the basics, albeit very briefly, and then concentrates on the subject of treating patients.

However, the internal structure of the first, introductory part and the second, therapeutic one could not be more different, as the latter is rather poorly structured: some text appears twice and at least one block of text does not seem to have a coherent structure. Moreover, item number 11 on the list is written in the Greek vernacular, which is not commonly used in writing.

At first sight, it seems somewhat puzzling that a scribe would go through the very considerable effort of including the same content twice while aiming to produce a book that is intent on being concise and comprehensive at the same time. After all, there is no logical reason why someone would produce a codex this small, which is very inconvenient to read, other than portability. Or to put it another way, if someone wanted to compile a book that a physician or a traveller could carry with them with ease, in order to include all the relevant content one might need, would he not ensure that the available space was managed more efficiently?

The obvious answer would be that this duplication was a mistake - i.e. a scribe not noticing that he was essentially copying the same text twice. This would also make sense given that the shorter item, i.e. item nine, comes first. By the time the scribe reached the longer version of the text in their model, they would already have copied the shorter one, and there

7 This item also includes a brief collection of remedies, pp. 41-4.

8 Nutton and Zipser (2010). 


\section{Barbara Zipser}

would be no way to undo this. Moreover, it would be useful to include all the additional content that could be found in the longer one.

But perhaps the answer is even more straightforward than that. It is actually quite common for manuscripts to contain two or more texts covering very similar content. An example from Wellcome Collection would be MS. MSL.60, which preserves a number of texts on urine diagnosis. ${ }^{9}$ There is also a whole genre of medical manuscripts attributed to Byzantine xenons, in which one can find similar developments. ${ }^{10}$

Thus, even though room was scarce and book production expensive, there was a genre of literature that was thematic, in the same way as other volumes might contain works by a specific author. Having several texts on the same topic was apparently seen as better than having just one.

This appears to be the more likely explanation, even though MS.MSL.14 is just a small handbook. Here, literary convention was more important than practical use. The person who produced this handbook did not reinvent the way it was structured; he applied existing standards and just shrank everything to size. The advantage of such a practice would, of course, have been that the general structure of the volume would have made sense to anyone who might use it.

The next question to be addressed is whether the second, therapeutic half of the book appears in other witnesses. It is not recorded anywhere, but, given the current state of cataloguing, it is certainly possible that a previously unknown manuscript might emerge at some later date. However, some content from item nine appears independently in a number of other manuscripts, as it is very closely related to one of the so-called xenonika. ${ }^{11}$ This could be a possible link, since the transmission of item 11 also seems to be somehow associated with the transmission of the xenonika. ${ }^{12}$

Here is a slightly standardised edition of the text. ${ }^{13}$ Where the text has been edited by me, the manuscript reading can be found in brackets with the sigla L (=MS.MSL.14).

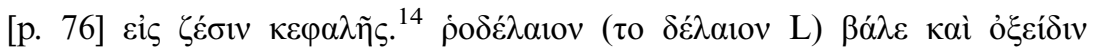

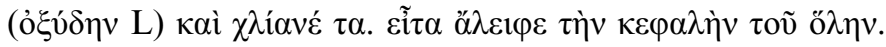

On an overheated head. Take rose oil and vinegar and make it smooth. Then rub it on his entire head.

9 Bouras-Vallianatos (2015: 293).

10 See, for example, Bennett (2003: 243).

11 Bennett (2003: 406ff).

12 See n. 10.

13 As far as the spelling is concerned, I have followed the same principles as in my edition of John Archiatros. See Zipser (2009: 20ff).

14 Almost identical to John Archiatros, Iatrosophion, $\omega$, 3, ed. Zipser (2009) 177.8-9. Xenonika, Rx4, ed. Bennett (2003) 409, contains the standard Greek version of the text. 


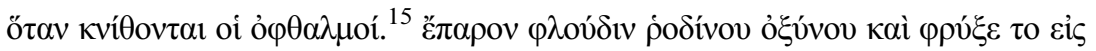

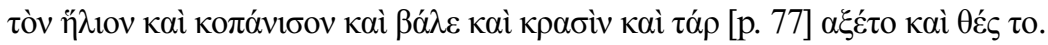

When the eyes itch. Take the peel of a sour pomegranate and dry it in the sun and grind it up and also add wine and mix and apply it.

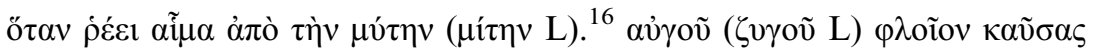

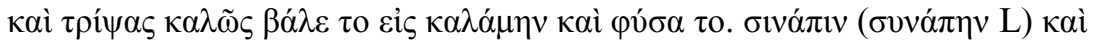

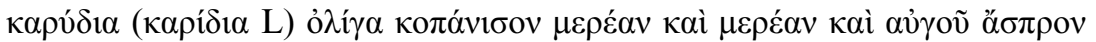

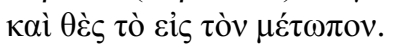

When blood flows from the nose. Burn the shell of an egg and grind it nicely and put it into a reed and blow it <into the nostril>. Grind mustard seeds and some walnuts one after the other and egg white and put it on the forehead.

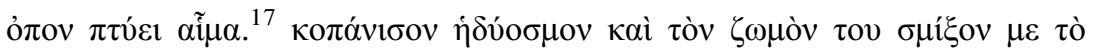

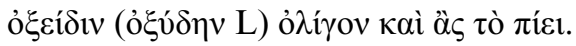

When <someone> spits blood. Grind up mint and mix its juice with a little bit of vinegar and let him drink it.

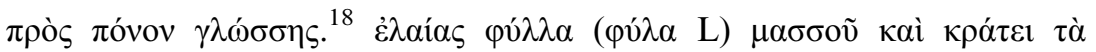

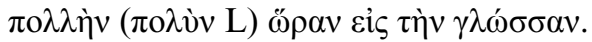

For pain in the tongue. Chew olive-tree leaves and hold them on the tongue for a long time.

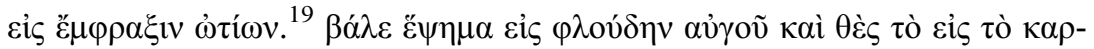

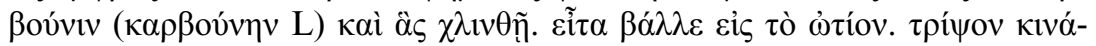

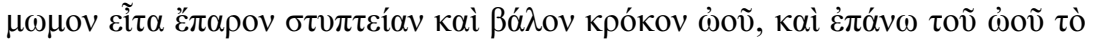

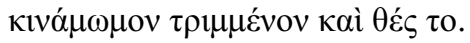

For blocked ears. Put broth in an egg shell and put it on coals and let it get warm. Then put it into the ear. Grind cinnamon then take an astringent substance and add egg yolk, and also <add $>$ ground cinnamon on top of the egg and apply it.

15 Coincides with parts of John Archiatros, Iatrosophion, $\omega$, 5, ed. Zipser (2009) 178.10-11. It is a rephrased version of Xenonika, Rx9, ed. Bennett (2003) 411.

16 Coincides with parts of John Archiatros, Iatrosophion, $\omega$, 7, ed. Zipser (2009) 179.5-9. Xenonika, Rx11, ed. Bennett (2003) 412, contains a similar text.

17 Mostly identical with John Archiatros, Iatrosophion, $\omega$, 8, ed. Zipser (2009) 179.12-13. Xenonika, Rx14, ed. Bennett (2003) 413, is quite similar.

18 Mostly identical with John Archiatros, Iatrosophion, $\omega$, 9, ed. Zipser (2009) 179.14-15. Very similar to Xenonika, Rx17, ed. Bennett (2003) 414.

19 Very similar to John Archiatros, Iatrosophion, $\omega$, 15, ed. Zipser (2009) 182.3-8. 


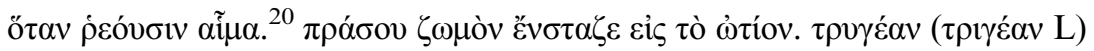

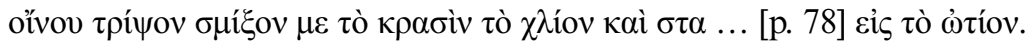

When blood flows $<$ from the ears $>$. Put drops of leek juice into the ear. Grind up the sediment of wine, mix it with warm wine and $<$ drip it $>$ into the ear.

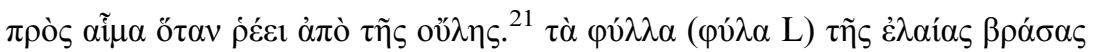

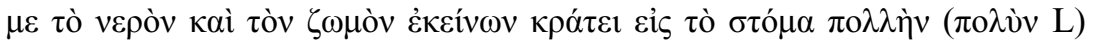

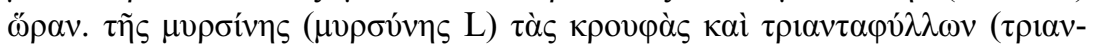

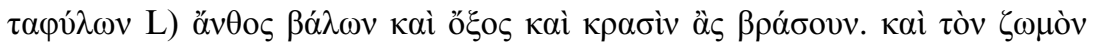

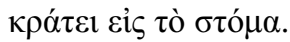

For bleeding gums. Boil the leaves of an olive tree with water and keep the decoction of it in the mouth for a long time. Put the shoots of myrtle and rose flowers in vinegar and wine and let it boil, and keep the decoction in the mouth.

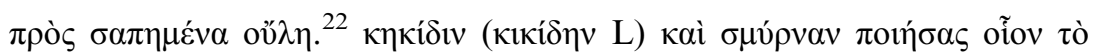

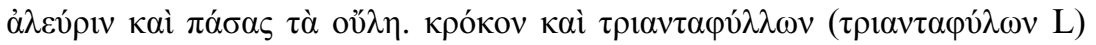

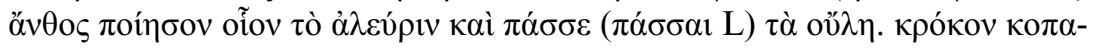

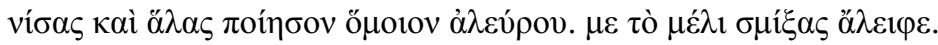

For rotting gums. Make oak-gall and myrrh like flour and apply on the gums. Make saffron and rose flowers like flour and apply to the gums. Grind up saffron and salt and make it like flour. Mix with honey and apply.

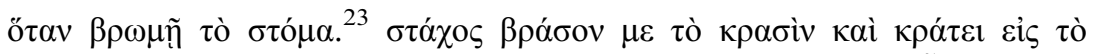

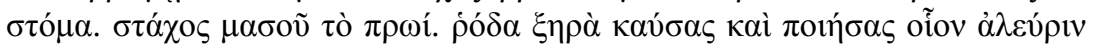
$\tau \rho i ́ \beta \varepsilon \tau$ сò̀ $\varsigma$ ỏóv $\tau \alpha \varsigma$.

When the mouth has a bad odour. Boil base horehound with wine and apply to the mouth. Chew base horehound in the morning. Burn dried roses and make them like flour and rub on the teeth.

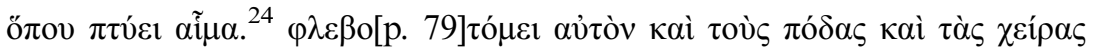

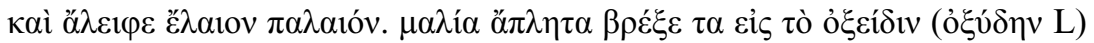

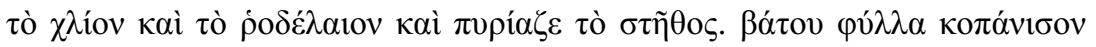

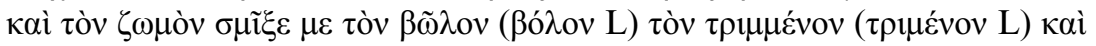

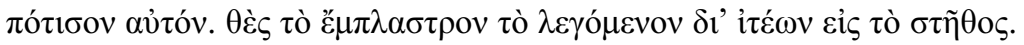

20 Very similar to John Archiatros, Iatrosophion, $\omega$, 23, ed. Zipser (2009) 185.16-18.

21 Coincides with John Archiatros, Iatrosophion, $\omega$, 30, ed. Zipser (2009) 189.16-19.

22 Coincides in part with John Archiatros, Iatrosophion, $\omega$, 31, ed. Zipser (2009) 190.4-9.

23 Coincides with John Archiatros, Iatrosophion, w, 34, ed. Zipser (2009) 191.10-15, but with some words transposed.

24 Coincides in part with John Archiatros, Iatrosophion, w, 36, ed. Zipser (2009) 192.18-193.9. 


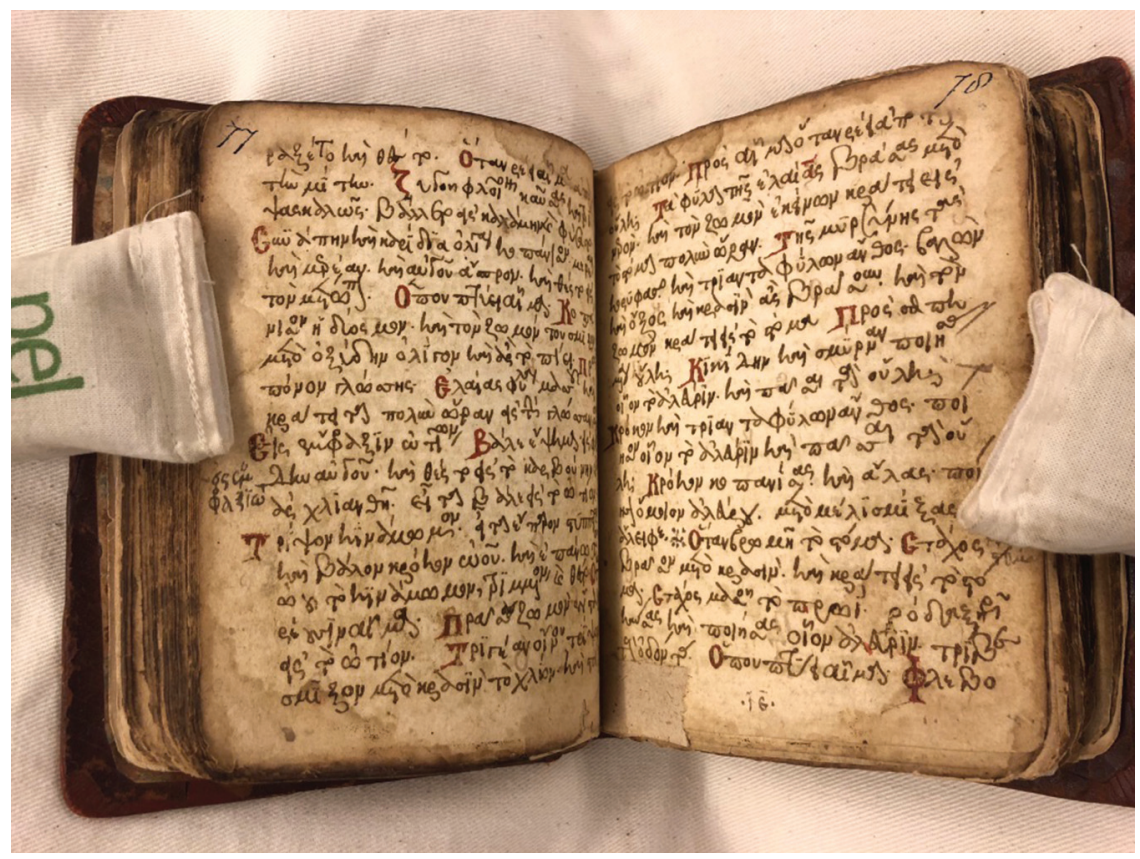

Figure 3.1 Londiniensis Wellcomensis MS.MSL.14, pp. 77-8.

Photograph by Petros Bouras-Vallianatos.

When $<$ the patient $>$ spits blood. Bleed them from the feet and hands and anoint with old olive oil. Soak unwashed hair in warm vinegar and rose oil and apply as a vapour bath to the chest. Grind bramble leaves and mix the juice with ground earth and let him drink. Put the plaster that is called 'from willows' on <the patient's $>$ chest.

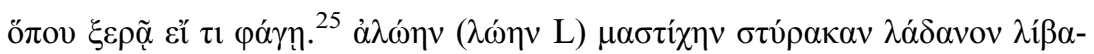

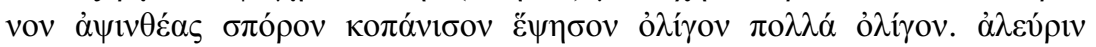

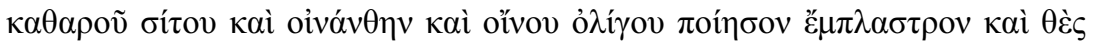

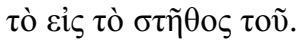

When someone vomits whatever he eats. Grind aloe, mastic, storax, ladanum, frankincense, wormwood and boil it a little <by which I mean $>$ very little. Make a plaster from clean bread flour and vine flower and a little wine and put it on his chest. 


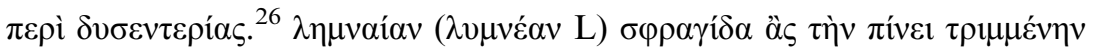

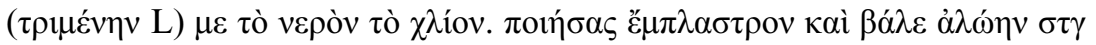

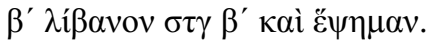

On dysentery. Let him drink Lemnian earth, ground up with warm water. Make a plaster and add two stagia of aloe, two stagia of frankincense, and broth.

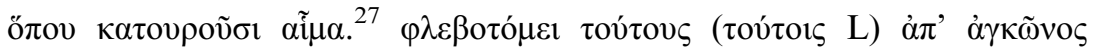

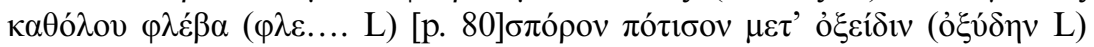

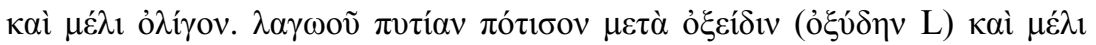
ỏ $\lambda$ ífov.

When they are urinating blood. Bleed them from the main vein on the elbow ... seed let him drink with vinegar and a little honey. Drink hare's rennet with vinegar and a little honey.

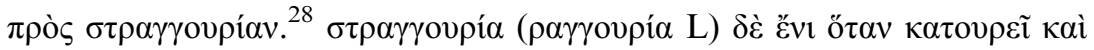

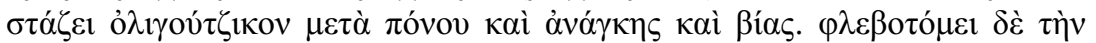

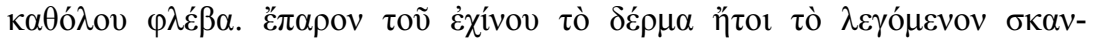

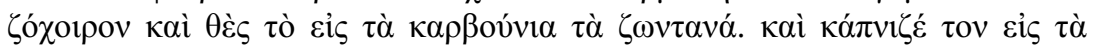
$\alpha i \delta$ oĩ $\alpha$, ö

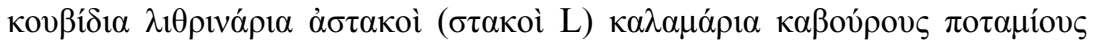

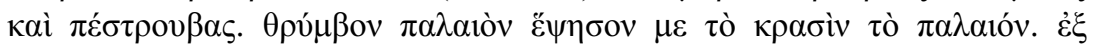

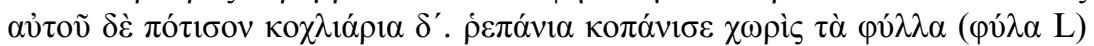

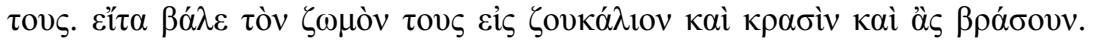

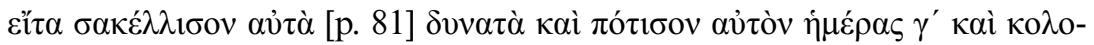

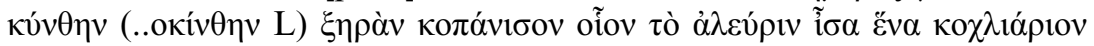

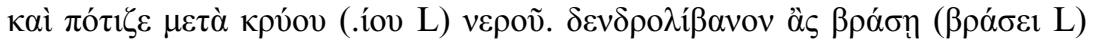

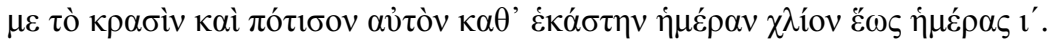

On strangury. Strangury is when someone urinates and only drips a tiny amount with pain, urgency, and much effort. Bleed him from the main vein. Take the skin of a hedgehog, that is the so-called skanzoxoiros and put it on hot coals. And apply the vapour to the groin, where he cannot urinate. Let his diet be balanced, that is bullhead fish, common pandora, lobster, squid, freshwater crabs and trout. Boil old summer savoury with old wine. Let him drink four spoonfuls of it. Grind radishes without their leaves. Then pour the juice into a pot with wine and let it boil. Then pound them forcibly and let him drink it for three days. And grind one spoonful of dry pumpkin like flour and let him drink it with cold water. Boil rosemary with wine and let him drink it warm every day for ten days.

26 Coincides with John Archiatros, Iatrosophion, $\omega$, 39, ed. Zipser (2009) 194.5-6, 195.3-4.

27 Coincides with John Archiatros, Iatrosophion, $\omega$, 46, ed. Zipser (2009) 199.3-6.

28 Coincides largely with John Archiatros, Iatrosophion, $\omega, 47$, ed. Zipser (2009) 199.7-200.4. 
ö

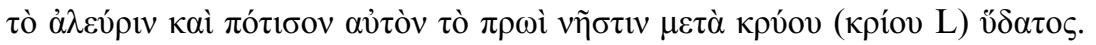

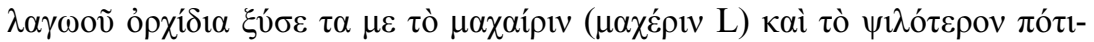

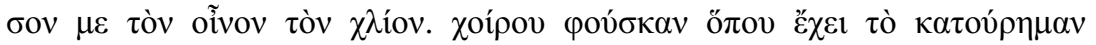

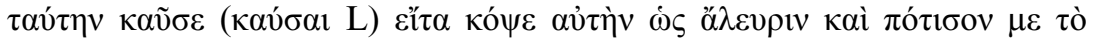

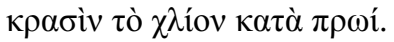

When someone urinates in his clothes. Burn the throat of a cock and make it like flour and let him drink it with cold water in the morning having fasted. Scrape the testicles of a hare with a knife and let him drink the fine particles with warm wine. Burn the bladder of a pig - where it keeps the urine - and then pound it like flour and let him drink it with warm wine.

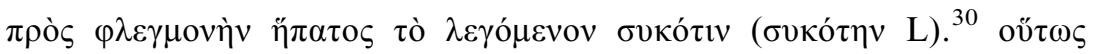

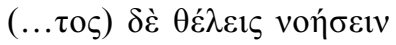

On inflammation of the liver, the so-called sykotin. You may recognise it like this.

As can easily be seen from the references in the footnotes, this text coincides in part with the vernacular version of John Archiatros, but it is much shorter. It does not contain any significant content that would not have been included in John's text. Some paragraphs also occur in a text associated with the xenons, as edited by David Bennett, however, the wording is not always exactly the same. Overall, it appears that the situation is comparable to that of the synoptic gospels: we know that there once was a common source which is today lost and then several intermediate stages of the transmission, but we do not have the evidence to reconstruct the exact dependencies.

For the second part of my paper, I would like to take a closer look at item ten on my list, which has not previously received any scholarly attention at all. The text starts and ends abruptly with pages missing or misplaced, so that we cannot be sure that this was indeed its original position in the codex.

These are the headings within the text in transcription:

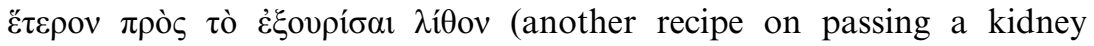
stone), p. 84;

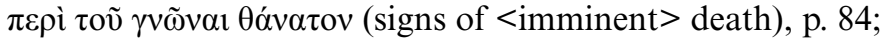

$\pi \varepsilon \rho \grave{~} \varphi \theta \varepsilon \tilde{i} \rho \alpha \varsigma$ (on lice), p. 85;

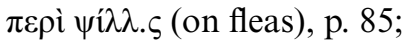

$\pi \rho$ ò $\varsigma \varepsilon v ́ \gamma o v \tau \alpha$ (on a fugitive), p. 85;

29 Coincides largely with John Archiatros, Iatrosophion, w, 48, ed. Zipser (2009) 200.5-11.

30 Coincides with John Archiatros, Iatrosophion, w, 49, ed. Zipser (2009) 200.12-13. 


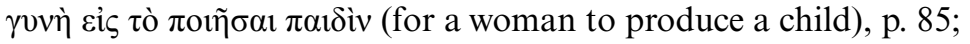

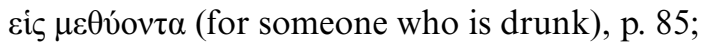

eis $\gamma \varepsilon v \tilde{\eta} \sigma \alpha 1$ (on conceiving), p. 85;

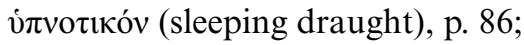

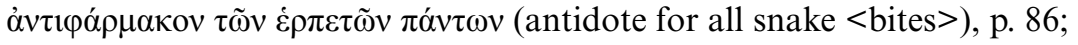

$\pi \varepsilon \rho i$ ióvov $\pi \lambda \varepsilon$ v́pov (pain in the ribs), p. 86;

$\pi \varepsilon \rho i ̀ ~ \tau o \tilde{~ \kappa \alpha v \sigma o \mu \varepsilon ́ v o v ~ v ं \pi o ̀ ~ \delta i ́ \psi \eta ~(o n ~ e x c e s s i v e ~ t h i r s t), ~ p . ~ 87 ; ~}$

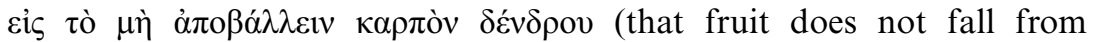
a tree), p. 87;

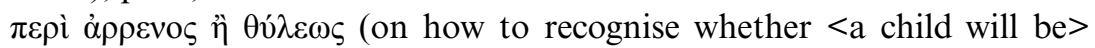
male or female), p. 87;

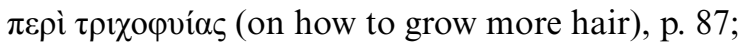

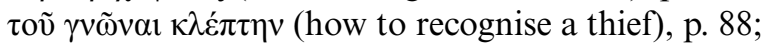

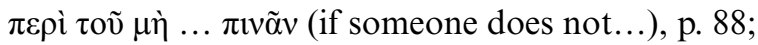

blank line, heading missing, p. 89;

$\pi \varepsilon \rho \grave{~} \grave{\varepsilon} \xi \omega \chi \alpha ́ \delta \omega v$ (on external haemorrhoids), p. 89;

$\pi \varepsilon \rho \grave{~} \dot{\sigma} \omega \chi \alpha \dot{\delta} \delta \omega v$ (on internal haemorrhoids), p. 89;

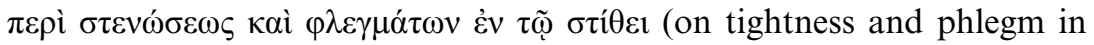
the chest), p. 89;

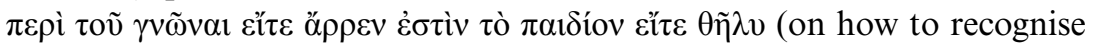
whether a child is male or female), p. 90;

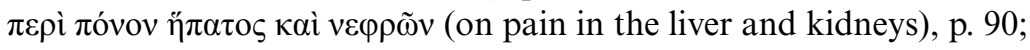

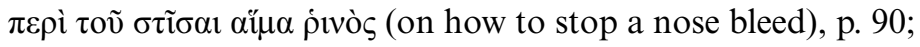

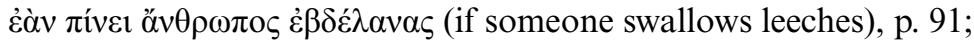

$\pi \rho$ ò $\varsigma$ óvov $\lambda v \gamma \mu$ oṽ (on a sore throat), p. 92;

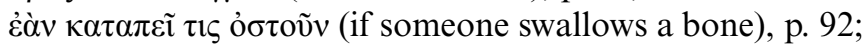

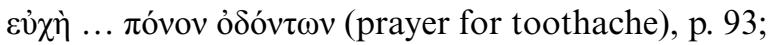

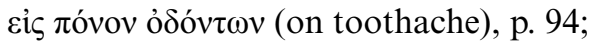

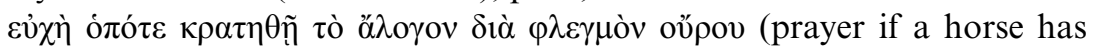
phlegm in the urine), p. 94;

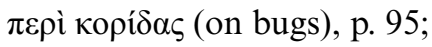

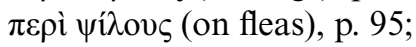

$\pi \varepsilon \rho \grave{~} \operatorname{\kappa o\mu } \omega . . v \alpha(?)$, p. 95;

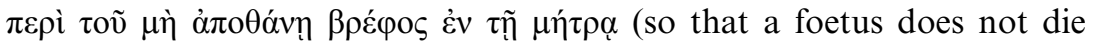
inside the womb), p. 95;

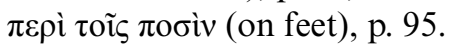

From this point onward, there are fewer clearly defined headings, as the focus shifts towards medication.

Even a brief look at the above list reveals that it is entirely chaotic. Only in four instances are paragraphs arranged in a thematic sequence: right at the start of the fragment, where 'another' remedy for kidney stones is mentioned, then the passages on external and internal haemorrhoids and finally two paragraphs on insects near the beginning and the end. Moreover, three chapters have no medical content: on a fugitive, on how to recognise a thief 
and a treatment for fruit trees. One chapter deals with veterinary medicine, which is not usually covered in standard medical collections. The content of the chapters is sometimes similar in scope and vocabulary to John Archiatros' text or the text of the collection described above. However, a significant proportion is completely different, in that it is largely related to magic. On the whole, it is quite similar to the sheets of paper that were subsequently added to the codex, and also to some iatrosophia of the more disorganised type. $^{31}$

As mentioned above, because of the damage to the codex we cannot be sure where these pages originally belonged. Generally speaking, there appears to have been a tendency for rough drafts or badly organised collections such as this to be added to the end of a therapeutic text. ${ }^{32}$ Indeed this may have been the case here, as the end of John Archiatros' text is likewise missing from the codex.

To illustrate the content, style and scope of the text, see, for instance, this extract from page 85 of the codex:

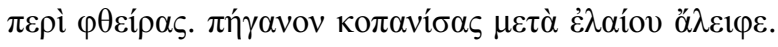

On lice. Grind rue with oil and apply.

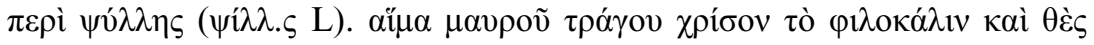

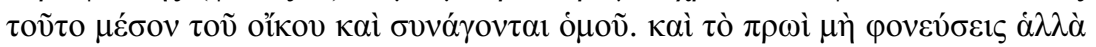

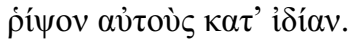

On fleas. Apply the blood of a black he-goat on a broom and put it in the middle of the house and they will congregate there. And in the morning you should not kill them but throw them out individually.

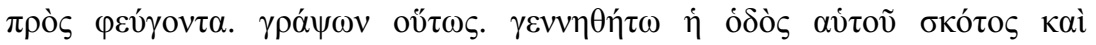

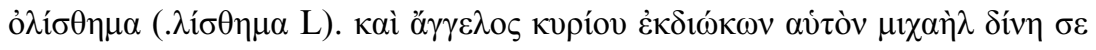

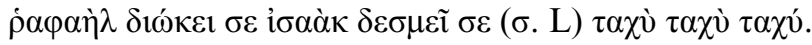

On a fugitive. Write thus: Let his way be darkness and stumbling and may the angel of the Lord pursue him. May Michael strike you, Raphael hound you <and> Isaac bind you quickly, quickly, quickly.

The first paragraph contains a simple pharmaceutical treatment for a condition that is often mentioned in medical texts. It is rather brief, which makes it appear slightly out of place in a work by a late antique encyclopaedist

31 See Zipser (2019) for an in-depth discussion of the matter. See also Ieraci Bio (1982); Tselikas (1995); Garzya (2003); Touwaide (2007); Marchetti (2011); and Oberhelman (2015).

32 See, for instance, the original version of John Archiatros, Iatrosophion, x, 184ff, ed. Zipser (2009) $156 \mathrm{ff}$ or in the transmission of Alexander of Tralles' Therapeutics in Florentinus Laurentianus gr. plut. 74.10 (fourteenth century), ff. 330r-344v. The same phenomenon can also be observed in other texts. 


\section{4}

Barbara Zipser

such as Paul of Aegina, but it would be perfectly consistent with the work of John Archiatros. That said, John's text does not mention this specific recipe for the treatment of head lice.

The next paragraph also covers a medical topic, describing a trap for fleas which uses blood as a bait and which seems quite sensible. However, the instruction to use blood from a black he-goat is clearly rooted in magic, and there is no mention of any more complex pharmacological treatment. The third paragraph is entirely of a magical nature, as it describes an amulet, including a curse. Moreover, it is clearly not a medical matter.

The remainder of the text is of a very similar nature, and one is left wondering how and why it was included in the codex at all. Given the length of the collection of paragraphs, it does not appear likely that these were originally notes made by previous owners that were added on some blank space in the manuscript and then copied by mistake. Someone must have made a conscious decision to copy the text and include it in a book. It is, however, quite possible that the text was originally noted down by a user on a quire of spare pages, which were then inserted into a volume that was subsequently used as a master copy, just as the final pages were later on inserted into MS.MSL.14.

But, in any case, the professional scribe who would later go on to produce MS.MSL.14, or the person who commissioned the book, decided to keep the collection as it stood, despite its obvious shortcomings. On the whole, this created a corpus of therapeutic texts of rather diverse scope. Of these, text eight would be by far the most sophisticated and polished. It contains recipes such as this one on p. 49 (in a slightly edited form, with the original manuscript readings in brackets):

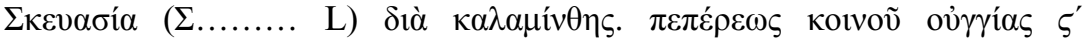

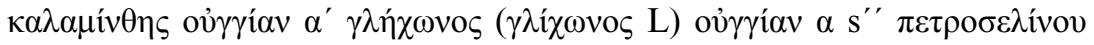

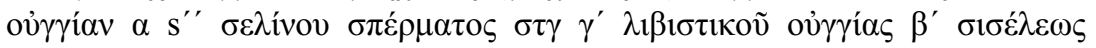

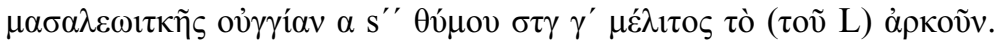

Recipe < for medication made> from mint: common pepper six ounces, mint one ounce, pennyroyal one and a half ounces, parsley one and a half ounces, celery seed three stagia, lovage two ounces, Massilian hartwort one and a half ounces, thyme three stagia, <and $>$ a sufficient quantity of honey.

At the opposite end of the spectrum, text ten is clearly the least accomplished. Texts nine and eleven would be somewhere in between but closer to text eight in scope and content.

Overall, the therapeutic section of this manuscript caters for diverse audiences, ranging from those who would not necessarily have any medical training (see, for instance, the amulets and the content relating to magic) to skilled doctors, or pharmacists for that matter. Throughout the volume, the materia medica described is generally of a simpler nature than for instance in Galen or 
Paul of Aegina, but still quite varied; the samples translated above are representative in that respect. What is most striking is that only very few imported goods such as cinnamon are mentioned. All of this gives a very coherent picture of the intended audience of the volume. The fact that the book had suffered serious wear and tear is entirely consistent with these findings.

\section{Bibliography}

Bennett, D. 2003. Xenonika: Medical Texts Associated with Xenones in the Late Byzantine Period. University of London: PhD thesis, available at https://ethos.bl.uk/Order Details.do?uin=uk.bl.ethos.404391 (accessed, 23 May 2019).

Bouras-Vallianatos, P. 2015. 'Greek Manuscripts at the Wellcome Library in London: A Descriptive Catalogue', Medical History 59.2: 275-326.

Garzya, A. 2003. 'Pour l'édition des iatrosophia démotiques', in A. Garzya and J. Jouanna (eds.), Trasmissione e ecdotica dei testi medici greci. Naples: D’Auria, $165-72$.

Ieraci Bio, A. M. 1982. 'Testi Medici di Uso Strumentale', Jahrbuch der Österreichischen Byzantinistik 32: 33-43.

Marchetti, M. 2011. 'La trasmissione della cultura scientifica greca a Bisanzio. Codici di medicina e astronomia della Biblioteca Medicea Laurenziana', in M. Bernabò (ed.), Voci dell'oriente. Miniature e testi classici da Bisanzio alla Biblioteca Medicea Laurenziana. Florence: Polistampa, 121-6.

Nutton, V. and Zipser, B. 2010. 'MSL 14: A Wellcome Manuscript of a Medical Practitioner', in V. Boudon-Millot and A. Roselli (eds.), L'ecdotique des textes médicaux grecs: réception et traduction. Naples: D'Auria, 259-70.

Oberhelman, S. M. 2015. 'Towards a Typology of Byzantine and Post-Byzantine Healing Texts', Athens Journal of Health 2.2: 133-46.

Touwaide, A. 2007. 'Byzantine Hospital Manuals (Iatrosophia) as a Source for the Study of Therapeutics', in B. Bowers (ed.), The Medieval Hospital and Medical Practice. Aldershot: Ashgate, 147-73.

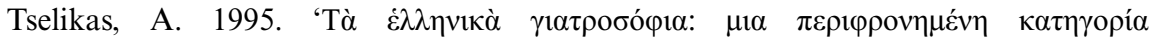

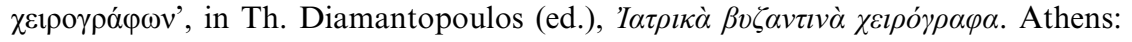
Domos, 57-69.

Zipser, B. (ed.). 2009. John the Physician's Therapeutics: A Medical Handbook in Vernacular Greek. Leiden: Brill.

Zipser, B. 2013. 'Magic, Infidelity and Secret Annotations in a Cypriot Manuscript of the Early Fourteenth Century (Wellcome MSL 14)', in S. Oberhelman (ed.), Dreams, Healing, and Medicine in Greece: From Antiquity to the Present. Farnham: Ashgate, 251-66.

Zipser, B. 2019. 'Galen in Byzantine iatrosophia', in P. Bouras-Vallianatos and B. Zipser (eds.), Brill's Companion to the Reception of Galen. Leiden: Brill, 111-23. 